\title{
Resonance assignment of PsbP: an extrinsic protein from photosystem II of Spinacia oleracea
}

\author{
Adriana Rathner ${ }^{1,2} \cdot K$ ousik Chandra ${ }^{1} \cdot$ Petr Rathner $^{1,2} \cdot$ Michaela Horničáková $^{1,3}$. \\ Judith Schlagnitweit ${ }^{1,4} \cdot$ Jaroslava Kohoutová $^{2,5} \cdot$ Rüdiger Ettrich $^{2,5}$. \\ Norbert Müller ${ }^{1,2}$
}

Received: 11 December 2014/Accepted: 11 April 2015/Published online: 23 April 2015

(C) The Author(s) 2015. This article is published with open access at Springerlink.com

\begin{abstract}
PsbP (23 kDa) is an extrinsic eukaryotic protein of photosystem II found in the thylakoid membrane of higher plants and green algae. It has been proven to be indispensable for proper functioning of the oxygen evolving complex. By interaction with other extrinsic proteins (PsbQ, PsbO and PsbR), it modulates the concentration of two cofactors of the water splitting reaction, $\mathrm{Ca}^{2+}$ and $\mathrm{Cl}^{-}$. The crystallographic structure of PsbP from Spinacia oleracea lacks the N-terminal part as well as two inner regions which were modelled as loops. Those unresolved parts are believed to be functionally crucial for the binding of PsbP to the thylakoid membrane. In this NMR study we report ${ }^{1} \mathrm{H},{ }^{15} \mathrm{~N}$ and ${ }^{13} \mathrm{C}$ resonance assignments of the backbone and side chain atoms of the PsbP protein. Based on these data, an estimate of the secondary structure has been made. The structural motifs found fit the resolved parts of the crystallographic structure very well. In
\end{abstract}

Norbert Müller

norbert.mueller@jku.at

1 Institute of Organic Chemistry, Johannes Kepler University, Altenbergerstraße 69, 4040 Linz, Austria

2 Faculty of Science, University of South Bohemia, České Budějovice, Czech Republic

3 Present Address: Lohmann Animal Health, Heinz-LohmannStraße 4, 27472 Cuxhaven, Germany

4 Present Address: Centre de RMN à très Hauts Champs, Institut des Sciences Analytiques, Université de Lyon, 5 Rue de la Doua, 69100 Villeurbanne, France

5 Centrum of Nanobiology and Structural Biology, Institute of Microbiology, Academy of Sciences of the Czech Republic, Nové Hrady, Czech Republic addition, the complete assignment set provides preliminary insight into the dynamic regions.

Keywords PsbP · Photosystem II · Oxygen evolving complex $\cdot$ Dynamic regions $\cdot$ Intrinsic disorder

\begin{tabular}{|c|c|}
\hline \multicolumn{2}{|c|}{ Abbreviations } \\
\hline AEBSF & $\begin{array}{l}\text { 4-(2-Aminoethyl) benzenesulfonyl fluoride } \\
\text { hydrochloride }\end{array}$ \\
\hline BME & Eagle's basal medium \\
\hline EDTA & Ethylenediaminetetraacetic acid \\
\hline IPTG & Isopropyl $\beta$-D-1-thiogalactopyranoside \\
\hline LB & Lysogeny broth \\
\hline OD & Optical density \\
\hline OEC & Oxygen evolving complex \\
\hline PI & Protease inhibitors \\
\hline
\end{tabular}

\section{Biological context}

Photosystem II is a multi-protein, -lipid, and -pigment complex, which spans the thylakoid membrane of all photosynthetic organisms. Its protein fraction consists of two major parts, an intrinsic cluster of proteins and a set of extrinsic, "accessory", proteins. While the intrinsic proteins are highly conserved among the photosynthetic species, the extrinsic proteins have evolved, probably from their homologous cyanobacterial precursors, as adaptations to the different photosynthetic apparatus in eukaryotes as compared to prokaryotes (Shen et al. 1998; Enami et al. 2005).

The PsbP protein is located on the lumenal side of thylakoids, in the oxygen evolving complex (OEC) of 
photosystem II, which is the site of the water-splitting reaction yielding molecular oxygen. PsbP is part of a barrier of extrinsic proteins, which surround the reaction centre with the $\mathrm{Mn}_{4} \mathrm{CaO}_{5}$ cluster at the lumenal thylakoid surface.

In total four extrinsic proteins have been found in most higher plants: PsbO (30 kDa), PsbP (23 kDa), PsbQ $(16.5 \mathrm{kDa})$ and PsbR (10 kDa). The biggest of these, PsbO, is conserved across the all photosynthetic phyla, unlike the remaining three extrinsic proteins. The exact binding topology and interactions of these proteins still remain unclear, but recently more experimental data have yielded a clearer picture of the assembly of the entire OEC (Bricker et al. 2012; Järvi et al. 2013; Ido et al. 2014; Nishimura et al. 2014; Mummadisetti et al. 2014).

One known function of PsbP is controlling the concentrations of two co-factors of water oxidation- $-\mathrm{Ca}^{2+}$ and $\mathrm{Cl}^{-}$(Popelkova and Yocum 2007). Binding of PsbP to the thylakoid membrane induces structural changes, which are necessary for stable oxygen production during photosynthesis. The N-terminal segment of PsbP is indispensable for this conformational change to occur. When the PsbP protein is deprived of the 15 amino acids at the $\mathrm{N}$-terminus, it is no longer capable of changing the topology of the membrane and the oxygen production decreases dramatically. In this case, it has been shown that PsbQ can compensate such a defect in the PsbP protein and helps to restore the levels of oxygen being released (Ifuku et al. 2011; Kakiuchi et al. 2012; Tomita et al. 2009). Preliminary studies in our group have provided the first solution structure of PsbQ. (Horničáková et al. 2011; Rathner 2013)

The three dimensional structure of PsbP from Spinacia oleracea has been resolved recently by X-ray crystallography at high resolution (1.98 ̊) (Kopecký et al. 2012; Kohoutová et al. 2009), see Fig. 1. The resolved part of the structure compares very well with an earlier structure of PsbP from Nicotiana tabacum (Ifuku et al. 2004). The electron density was not resolved in the N-terminal residues (1-19) and in two internal sections (res. 94-111 and 139-143), although the crystal did not contain any degradation products. Additional data from Raman spectroscopy and molecular dynamics simulation suggested a dynamic nature for these regions. The $\mathrm{N}$-terminus was modeled to contain a $\beta$-sheet element and the two unresolved internal regions to form two loops. Intrinsic disorder of the N-terminal part would be in accordance with its suggested function (Tomita et al. 2009; Ido et al. 2012).

In this paper we present the first NMR resonance assignment of PsbP as a foundation for further solution NMR studies of this protein, which will ultimately include interaction experiments with co-factors and other $\mathrm{Psb}$ proteins.

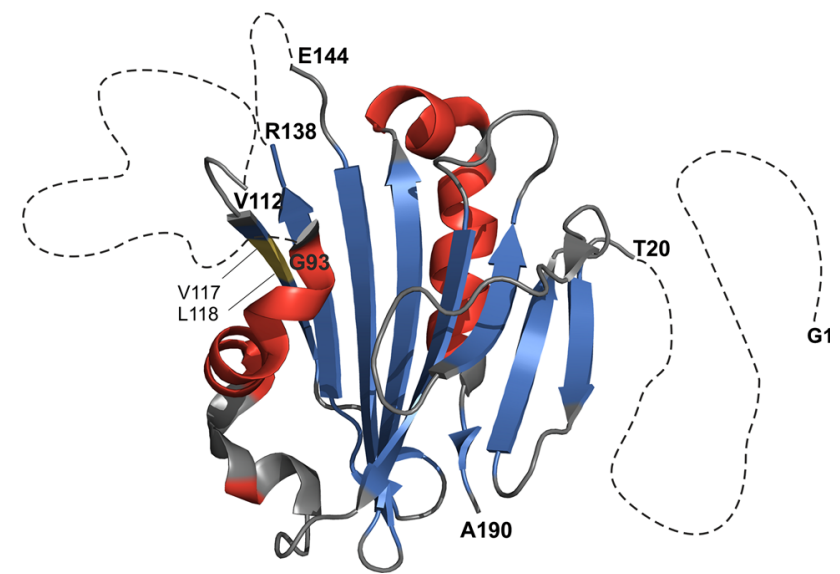

Fig. 1 Cartoon representation of the X-ray crystallographic structure of PsbP (PDB ID: 2VU4) (Kopecký et al. 2012). The inner four stranded anti-parallel $\beta$-sheet core is surrounded by five short $\alpha$ helices. The missing segments, labeled at the adjacent residues, are represented as dotted lines. The residues G1, V117 and L118, which are highlighted as well, could not be assigned by NMR. Numbering includes the four amino acids remaining from the His tag linker. The image was created using PyMOL (The PyMOL Molecular Graphics System, version 1.5.0.4 Schrödinger, LLC) from PDB ID: 2VU4

\section{Methods and experiments}

\section{Protein expression and purification}

The expression protocol followed Kohoutová et al. (2009) with some modifications. The gene coding for PsbP was included in the JR3133 plasmid, which also includes a His 6 tag attached to the N-terminus of the protein. The transformed $E$. coli BL21DE3 cells were grown in $25 \mathrm{ml}$ of $\mathrm{LB}$ medium (Kanamycin, $30 \mu \mathrm{g} / \mathrm{ml}$ ) as an overnight culture. After $12 \mathrm{~h}$ of cultivation at $37{ }^{\circ} \mathrm{C}$, the culture was diluted 1:100 and used to inoculate $1 \mathrm{~L}$ of fresh $\mathrm{LB}$ medium. When the optical cell density reached 1 (after 2-3 h of cultivation at $37^{\circ} \mathrm{C}$ with stirring at $150 \mathrm{rpm}$ ), the culture was centrifuged (45 min, $4000 \mathrm{~g}, 30^{\circ} \mathrm{C}$ ). The pellet was resuspended in the corresponding amount of M9 medium containing $(98 \%){ }^{15} \mathrm{~N}$ ammonium sulfate (Sigma Aldrich) for the singly labeled protein and-in the case of doubly labeled protein production- $(99 \%)$ universally ${ }^{13} \mathrm{C}$ labeled glucose (Sigma Aldrich). In both cases, the minimal medium was spiked with $1 \mathrm{ml}$ of vitamin mixture (BME vitamins $100 \times$ solution). The cells were grown for $1 \mathrm{~h}$ at $37{ }^{\circ} \mathrm{C}$ and then induced with $1 \mathrm{mM}$ IPTG. After induction, the cultivation temperature was lowered to $28{ }^{\circ} \mathrm{C}$ in order to prevent the undesirable formation of inclusion bodies. The cells were afterwards incubated overnight extending the total incubation time to $24 \mathrm{~h}$, where an OD of 3 was achieved.

The harvested pellets were resuspended in $50 \mathrm{ml}$ of icecold phosphate buffer $\left(20 \mathrm{mM} \mathrm{KH_{2 }} \mathrm{PO}_{4}, 500 \mathrm{mM} \mathrm{NaCl}\right.$, $20 \mathrm{mM}$ imidazole, $1 \mathrm{mM}$ AEBSF, pH 7.4) and repeatedly 
sonicated on ice to release the soluble protein fraction. The lysate was filtered through a GVS filter (pore size $0.22 \mu \mathrm{m}$ ) to remove insoluble cell debris.

Since the protein included an $\mathrm{N}$-terminal $\mathrm{His}_{6}$ tag, the first purification step was affinity chromatography using a $\mathrm{Ni}$ Sepharose High Performance (GE Healthcare) column charged with $\mathrm{NiSO}_{4}$ and equilibrated with the binding buffer A $\left(20 \mathrm{mM} \mathrm{KH}_{2} \mathrm{PO}_{4}, 500 \mathrm{mM} \mathrm{NaCl}, 20 \mathrm{mM}\right.$ imidazole, $\mathrm{pH}$ 7.4). The lysate was applied to the column and immediately after the elution of the flow-through volume, $\mathrm{His}_{6}$-PsbP was eluted by a linear gradient of elution buffer A $(20 \mathrm{mM}$ $\mathrm{KH}_{2} \mathrm{PO}_{4}, 500 \mathrm{mM} \mathrm{NaCl}, 500 \mathrm{mM}$ imidazole, $\mathrm{pH}$ 7.4). The His-PsbP containing eluates were combined and concentrated with Amicon Ultra-15 filters (cut-off $>10 \mathrm{kDa}$ ) and swapped into binding buffer $\mathrm{B}(20 \mathrm{mM}$ Bis Tris, $1 \mathrm{mM}$ EDTA, pH 6.0). The protein mixture was loaded onto a cation-exchange SP Sepharose Fast Flow column (GE Healthcare), which was washed with the binding buffer B. The elution was achieved with a linear gradient of elution buffer B (20 mM Bis Tris, 1 mMEDTA, $1 \mathrm{M} \mathrm{NaCl}$, pH 6.0).

The eluted $\mathrm{His}_{6}-\mathrm{PsbP}$ was concentrated to $2.3 \mathrm{mg} / \mathrm{ml}$ in $11 \mathrm{ml}$ and swapped into the tag cleavage buffer $(20 \mathrm{mM}$ Bis Tris, $100 \mathrm{mM} \mathrm{NaCl}, \mathrm{pH}$ 6.0). The $\mathrm{His}_{6}$ tag was cleaved off by incubation with human plasma thrombin (Sigma Aldrich, $1.5 \mathrm{U}$ per $1 \mathrm{mg}$ of protein) for $3 \mathrm{~h}$ at $25^{\circ} \mathrm{C}$. The enzymatic digestion was quenched by addition of protease inhibitors (AEBSF). To remove the cleaved tag and the protease, size exclusion chromatography was employed as the last purification step. The mixture was loaded onto a Superdex 75 Prep Grade column (GE Healthcare) and pure PsbP was eluted with the running buffer $(20 \mathrm{mM}$ Bis Tris, $200 \mathrm{mM} \mathrm{NaCl}, \mathrm{pH} \mathrm{6.0)}$ under constant flow of $0.3 \mathrm{ml} / \mathrm{min}$ after $3 \mathrm{~h}$. Four additional amino acids (GSHM) from the $\mathrm{His}_{6}$ tag linker/cleavage site remained at the $\mathrm{N}$-terminus of a final PsbP sample, bringing the total amino acid count to 190. The numbering used in this paper refers to the sequence of this recombinant protein.

\section{NMR experiments}

All spectra were recorded on a $700 \mathrm{MHz}$ Bruker Avance III spectrometer equipped with a TCI cryoprobe. The uniformly ${ }^{15} \mathrm{~N},{ }^{13} \mathrm{C}$ labeled PsbP samples were exchanged into the NMR buffer (20 mM Bis Tris, $1 \mathrm{mM}$ EDTA, $0.05 \mathrm{mM}$ $\mathrm{NaN}_{3}, \mathrm{pH} 6.0,10 \% \mathrm{D}_{2} \mathrm{O}$ ) to a final concentration of $500 \mu \mathrm{M}$ and transferred into $5 \mathrm{~mm}$ Shigemi tubes. The cleaving off of the $\mathrm{N}$-terminal part could be prevented by adding a protease inhibitors cocktail (complete Mini, EDTA free from Roche Diagnostics) to each NMR sample (concentration of 12 tablets per $100 \mathrm{ml}$ ). This proved essential in order to prevent sample degradation over the long measurement periods at elevated temperature (samples remained stable at $40{ }^{\circ} \mathrm{C}$ for typically 21 days).
For the backbone assignment, the following set of spectra was recorded: ${ }^{1} \mathrm{H}-{ }^{15} \mathrm{~N}$ HSQC, ${ }^{1} \mathrm{H}^{13}{ }^{13} \mathrm{C}$ HSQC, HNCO, HNCACB, CBCA(CO)NH (Grzesiek and Bax 1992), HNHA (Vuister and Bax 1993), ${ }^{1} \mathrm{H}-{ }^{15} \mathrm{~N}$ HSQC (Palmer et al. 1991). In order to achieve assignment of the aliphatic side chains, additional spectra were obtained: HCCH-COSY (Kay et al. 1993), H(CCO)NH, C(CO)NH (Montelione et al. 1992) and hCCH-TOCSY (Kay et al. 1993). All NMR spectra were processed using Bruker Topspin 3.1 or 3.2 software. The resonance assignment was carried out manually in the CARA (Keller 2004) and Sparky programs (Goddard and Kneller 2000). Secondary structure was analyzed using the online version of the Talos N program (Shen and Bax 2013), where the torsion angles $\varphi, \psi$ and $\chi$ are estimated from experimental backbone chemical shifts ( $\left.\mathrm{HN}, \mathrm{H}_{\alpha}, \mathrm{C}_{\alpha}, \mathrm{C}_{\beta}, \mathrm{CO}, \mathrm{N}\right)$.

\section{Assignments and data deposition}

\section{Assignments}

First NMR experiments were run at $293 \mathrm{~K}$ due to the low stability of the protein sample. However, ${ }^{1} \mathrm{H}-{ }^{15} \mathrm{~N}$ HSQC as well as preliminary triple resonance experiments were hampered by high signal overlap (see Fig. 2) and severe broadening of some resonances, which precluded any significant number of assignments. To overcome this problem, all NMR experiments for assignment were then recorded at elevated temperature of $313 \mathrm{~K}$ after optimizing sample stability by a protease-inhibitor stabilized preparation (see preceding Section). This temperature increase led to a drastic improvement of resolution through narrowing of many broad lines presumably from regions of protein subject to internal dynamics. When the sample is cooled down to $293 \mathrm{~K}$ again, identical poorly resolved spectra are obtained implicating that the broadening effects are reversible and due to the dynamic properties of the protein. Preliminary diffusion experiments at 293 and $313 \mathrm{~K}$ show that the diffusion coefficient measured respectively, increases only by a factor of 1.13 (the diffusion coefficients were corrected for the change in water viscosity at given temperatures). This indicates that there is no significant change in the aggregation state upon temperature increase. The spectral dispersion observed at high temperature is characteristic of a well-folded protein and already upon visual inspection a high $\beta$-sheet content of PsbP can be recognized. With the spectra recorded at $313 \mathrm{~K}, 96 \%$ of the backbone residues were assigned sequence-specifically (Fig. 2). Only, G1, V117, L118 and the amide nitrogen atoms of the 8 prolines could not be assigned. Assignment of side-chain resonances was accomplished to $81 \%$. Thus in total, $87 \%$ of all resonances were assigned. This 
Fig. 2 a ${ }^{1} \mathrm{H}_{-}{ }^{15} \mathrm{~N}$ HSQC spectrum of $500 \mu \mathrm{M}{ }^{15} \mathrm{~N},{ }^{13} \mathrm{C}$ PsbP at $313 \mathrm{~K}(20 \mathrm{mM}$ Bis Tris, $1 \mathrm{mM}$ EDTA, $0.05 \mathrm{mM} \mathrm{NaN}_{3}$, $\left.\mathrm{pH} 6.0,10 \% \mathrm{D}_{2} \mathrm{O}, \mathrm{PI}\right)$. The cross peaks are labeled with the respective residue types and numbers in the full recombinant protein sequence. The side chain $\mathrm{NH}$ peaks from the two tryptophan residues are labeled as well. Side chain $\mathrm{NH}_{2}$ peaks of glutamine and asparagine residues are connected by thin horizontal lines. $\mathbf{b}^{1} \mathrm{H}-{ }^{15} \mathrm{~N}$ HSQC of PsbP recorded at $293 \mathrm{~K}$ under otherwise identical conditions
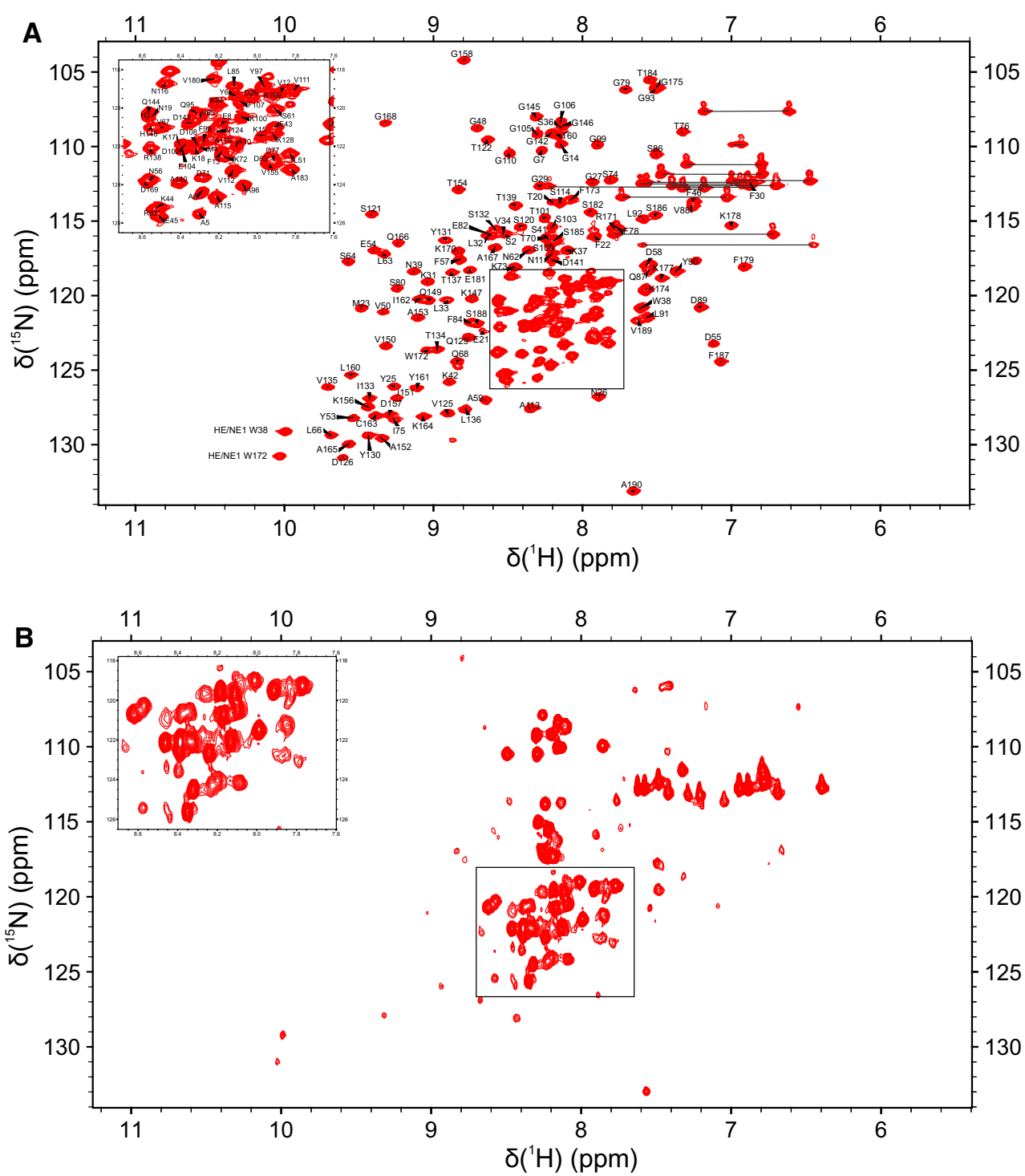

assignment enables us to proceed with the resolving of the solution structure of PsbP and to provide a basis for interaction studies between the Psb proteins. The assigned resonances have been deposited in the Biological Magnetic Resonance Data Bank under the Accession number 25379.

The central framed regions are magnified on the left sides of the spectra for better comparison. The spectra were recorded with two scans per increment and $2048 \times 256$ data points in the ${ }^{1} \mathrm{H}$ and ${ }^{15} \mathrm{~N}$ dimensions, respectively.

\section{Secondary structure}

Chemical shift based analysis of secondary structure elements was performed using the online platform version of Talos N (Shen and Bax 2013). The respective propensities of the three main secondary structure categories- $\alpha$-helix, $\beta$-sheet and random coil were compared with the available crystallographic structure of PsbP (PDB ID: 2VU4) (Kopecký et al. 2012) as represented in Fig. 3. The juxtapositioning yielded almost perfect agreement within the crystallographically well-resolved $\beta$-sheet core and $\alpha$-helices. From the NMR chemical shifts the secondary structures of the segments which were not deducible from the crystallographic electron densities, were estimated to be random coil in solution by Talos $\mathrm{N}$. These results are corroborated by experimental NMR data at lower temperatures $(293 \mathrm{~K})$, where only resonances of these flexible regions appear well resolved in ${ }^{1} \mathrm{H}-{ }^{15} \mathrm{~N}$ HSQC. Moreover no evidence for $\alpha$-helix or $\beta$-sheet patterns in those particular regions (residues 1-19, 94-111 and 139-143) was found in ${ }^{1} \mathrm{H}-{ }^{15} \mathrm{~N}$ NOESY-HSQC. The absence of peaks for V117 and L118 may be related to the dynamics of the nearby flexible loop. These findings confirm that under the above-mentioned conditions, the NMR sample contains a 

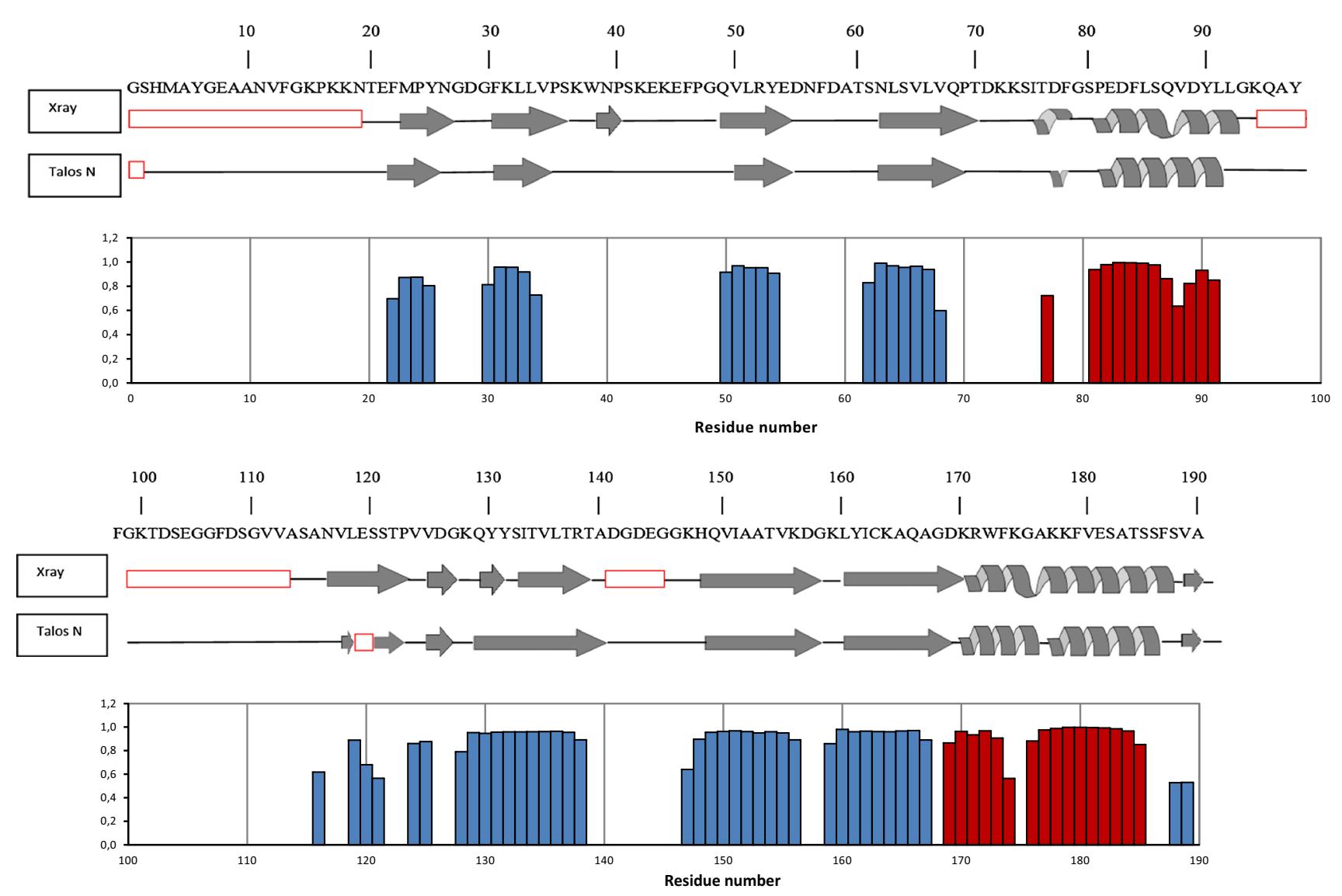

Fig. 3 Secondary structure of PsbP. Secondary structure obtained from the X-ray crystallographic structure (PDB ID: 2VU4) and Talos $\mathrm{N}$ prediction are compared. The bottom graph shows the probability of the secondary structure elements calculated by Talos N. Blue bars indicate predicted $\beta$-sheet, while red is used for $\alpha$-helices. Residues

largely well-folded PsbP protein, which is well suitable for further detailed structural investigations by NMR, especially of its dynamic properties. The ultimate target of this ongoing research is the elucidation of the interaction network of PsbP with other Psb proteins, in particular PsbQ, PsbO and PsbR as well as their contacts to the thylakoid and intrinsic parts of photosystem II.

Acknowledgments All NMR spectra were recorded at the NMR laboratory of the Upper Austrian-South Bohemian Research Infrastructure Center in Linz which was co-financed by the European Union via the project "RERI-uasb" EFRE RU2-EU-124/100-2010 (ETC Austria-Czech Republic 2007-2013, Project M00146). AR and PR acknowledge 3- and 4-months AKTION scholarships from OeAD, ICM, respectively. NM, RE, and JK were supported through AKTION projects (Projects 69p26 and 64p1). KC and NM acknowledge a Lise Meitner Grant from FWF, Project M1404-N28.

Open Access This article is distributed under the terms of the Creative Commons Attribution 4.0 International License (http:// creativecommons.org/licenses/by/4.0/), which permits unrestricted use, distribution, and reproduction in any medium, provided you give appropriate credit to the original author(s) and the source, provide a unresolved by X-ray or unassigned in NMR spectra are designated by red rectangles. Note that the numbering of the residues corresponds to the full recombinant protein sequence after tag cleavage, which compared to the wild type contains four additional amino acids (GSHM) at the N-terminus

link to the Creative Commons license, and indicate if changes were made.

\section{References}

Bricker TM, Roose JL, Fagerlund RD, Frankel LK, Eaton-Rye JJ (2012) The extrinsic proteins of Photosystem II. Biochim Biophys Acta 1817:121-142. doi:10.1016/j.bbabio.2011.07.006

Enami I, Suzuki T, Tada O, Nakada Y, Nakamura K, Tohri A, Ohta H, Inoue I, Shen JR (2005) Distribution of the extrinsic proteins as a potential marker for the evolution of photosynthetic oxygenevolving photosystem II. FEBS J 272:5020-5030. doi:10.1111/j. 1742-4658.2005.04912.x

Goddard TD, Kneller DG (2000) SPARKY 3. University of California, San Francisco

Grzesiek S, Bax A (1992) Improved 3D triple-resonance NMR techniques applied to a $31 \mathrm{kDa}$ protein. J Magn Reson 96:432-440. doi:10.1016/0022-2364(92)90099-S

Horničáková M, Kohoutová J, Schlagnitweit J, Wohlschlager C, Ettrich R, Fiala R, Schöfberger W, Müller N (2011) Backbone assignment and secondary structure of the PsbQ protein from photosystem II. Biomol NMR Assign 5:169-175. doi:10.1007/ s12104-011-9293-6 
Ido K, Kakiuchi S, Uno C, Nishimura T, Fukao Y, Noguchi T, Sato F, Ifuku K (2012) The conserved His-144 in the PsbP protein is important for the interaction between the PsbP N-terminus and the Cyt b559 subunit of photosystem II. J Biol Chem 287(31):26377-26387. doi:10.1074/jbc.M112.385286

Ido K, Nield J, Fukao Y, Nishimura T, Sato F, Ifuku K (2014) Crosslinking evidence for multiple interactions of the PsbP and PsbQ proteins in a higher plant photosystem II supercomplex. J Biol Chem. doi:10.1074/jbc.M114.574822

Ifuku K, Nakatsu T, Kato H, Sato F (2004) Crystal structure of the PsbP protein of photosystem II from Nicotiana tabacum. EMBO Rep 5:362-367. doi:10.1038/sj.embor.7400113

Ifuku K, Ido K, Sato F (2011) Molecular functions of PsbP and PsbQ proteins in the photosystem II supercomplex. J Photochem Photobiol, B 104:158-164. doi:10.1016/j.jphotobiol.2011.02.006

Järvi S, Gollan PJ, Aro EM (2013) Understanding the roles of the thylakoid lumen in photosynthesis regulation. Front Physiol 4:434. doi: $10.3389 /$ fpls.2013.00434

Kakiuchi S, Uno C, Ido K, Nishimura T, Noguchi T, Ifuku K, Sato F (2012) The PsbQ protein stabilizes the functional binding of the PsbP protein to photosystem II in higher plants. Biochim Biophys Acta 1817:1346-1351. doi:10.1016/j.bbabio.2012.01. 009

Kay LE, Xu GY, Singer AU, Muhandiram DR, Forman-Kay JD (1993) A gradient-enhanced HCCH-TOCSY experiment for recording side-chain $1 \mathrm{H}$ and $13 \mathrm{C}$ correlations in $\mathrm{H}_{2} \mathrm{O}$ samples of proteins. J Magn Reson B 10:333-337. doi:10.1006/jmrb.1993. 1053

Keller RLJ (2004) Optimizing the process of nuclear magnetic resonance spectrum analysis and computer aided resonance assignment. Diss. ETH No. 15947

Kohoutová J, Kutá Smatanová I, Brynda J, Lapkouski M, Revuelta JL, Arellano JB, Ettrich R (2009) Crystallization and preliminary crystallographic characterization of the extrinsic PsbP protein of photosystem II from Spinacia oleracea. Acta Cryst F 65:111-115. doi:10.1107/S1744309108040578

Kopecký V Jr, Kohoutová J, Lapkouski M, Hofbauerová K, Sovová Ž et al (2012) Raman spectroscopy adds complementary detail to the high-resolution X-ray crystal structure of photosynthetic PsbP from Spinacia oleracea. PLoS ONE. doi:10.1371/journal. pone.0046694
Montelione GT, Lyons BA, Emerson SD, Tashiro M (1992) An efficient triple resonance experiment using carbon-13 isotropic mixing for determining sequence-specific resonance assignments of isotopically-enriched proteins. $\mathrm{J}$ Am Chem Soc 114:10974-10975. doi:10.1021/ja00053a051

Mummadisetti MP, Frankel LK, Bellamy HD, Sallans L, Goettert JS, Brylinski M, Limbach PA, Bricker TM (2014) Use of protein cross-linking and radiolytic footprinting to elucidate PsbP and PsbQ interactions within higher plant photosystem II. PNAS 111:16178-16183. doi:10.1073/pnas.1415165111

Nishimura T, Uno C, Ido K, Nagao R, Noguchi T, Sato F, Ifuku K (2014) Identification of the basic amino acid residues on the PsbP protein involved in the electrostatic interaction with photosystem II. Biochim Biophys Acta 1837:1447-1453. doi:10.1016/j.bbabio.2013.12.012

Palmer AG III, Cavanagh J, Wright PE, Rance M (1991) Sensitivity improvement in proton-detected two-dimensional heteronuclear correlation NMR spectroscopy. J Magn Reson 93:151-170. doi:10.1016/0022-2364(91)90036-S

Popelkova H, Yocum CF (2007) Current status of the role of $\mathrm{Cl}^{-}$ion in the oxygen-evolving complex. Photosynth Res 93:111-121. doi:10.1007/s11120-006-9121-5

Rathner P (2013) NMR solution structure of the protein PsbQ from photosystem II. Master thesis JKU Linz

Shen Y, Bax A (2013) Protein backbone and sidechain torsion angles predicted from NMR chemical shifts using artificial neural networks. J Biomol NMR 56:227-240. doi:10.1007/s10858-0139741-y

Shen JR, Qian M, Inoue Y, Burnap RL (1998) Functional characterization of Synechocystis sp. PCC 6803 delta psbU and delta psbV mutants reveals important roles of cytochrome c-550 in cyanobacterial oxygen evolution. Biochemistry 37:1551-1558. doi:10.1021/bi971676i

Tomita M, Ifuku K, Sato F, Noguchi T (2009) FTIR evidence that the PsbP extrinsic protein induces protein conformational changes around the oxygen-evolving $\mathrm{Mn}$ cluster in photosystem II. Biochemistry 48:6318-6325. doi:10.1021/bi9006308

Vuister GW, Bax A (1993) Quantitative J correlation: a new approach for measuring homonuclear three-bond $\mathrm{J}$ (HNH alpha) coupling constants in $15 \mathrm{~N}$-enriched proteins. $\mathrm{J}$ Am Chem Soc 115:7772-7777. doi:10.1021/ja00070a024 